\title{
Selection of patients for myocardial perfusion scintigraphy based on fuzzy sets theory applied to clinical-epidemiological data and treadmill test results
}

P.S. Duarte ${ }^{1}$,

L.E. Mastrocolla ${ }^{2}$, P.S. Farsky², C.R.E.P.S. Sampaio ${ }^{2}$, P.A. Tonelli ${ }^{4}$, L.C. Barros ${ }^{6}$, N.R. Ortega ${ }^{5}$ and J.C.R. Pereira ${ }^{3}$

\author{
${ }^{1}$ Seção de Medicina Nuclear, ${ }^{2}$ Seção de Cardiologia, Fleury, Centro de Medicina \\ Diagnóstica, São Paulo, SP, Brasil \\ ${ }^{3}$ Departamento de Epidemiologia, Faculdade de Saúde Pública, \\ ${ }^{4}$ Instituto de Matemática e Estatística, ${ }^{5}$ Informática Médica, \\ Faculdade de Medicina, Universidade de São Paulo, São Paulo, SP, Brasil \\ ${ }^{6}$ Instituto de Matemática, Estatística e Computação Científica, \\ Universidade Estadual de Campinas, Campinas, SP, Brasil
}

\section{Correspondence}

P.S. Duarte

Seção de Medicina Nuclear

Rua Cincinato Braga, 232

01333-910 São Paulo, SP

Brasil

Fax: +55-11-5014-6788

E-mail: paulo.duarte@fleury.com.br

Research supported by FAPESP

(No. 01/04905-0).

$\ldots \ldots \ldots \ldots \ldots \ldots$

Received December 17, 2004 Accepted October 24, 2005

\begin{abstract}
Coronary artery disease (CAD) is a worldwide leading cause of death. The standard method for evaluating critical partial occlusions is coronary arteriography, a catheterization technique which is invasive, time consuming, and costly. There are noninvasive approaches for the early detection of CAD. The basis for the noninvasive diagnosis of CAD has been laid in a sequential analysis of the risk factors, and the results of the treadmill test and myocardial perfusion scintigraphy (MPS). Many investigators have demonstrated that the diagnostic applications of MPS are appropriate for patients who have an intermediate likelihood of disease. Although this information is useful, it is only partially utilized in clinical practice due to the difficulty to properly classify the patients. Since the seminal work of Lotfi Zadeh, fuzzy logic has been applied in numerous areas. In the present study, we proposed and tested a model to select patients for MPS based on fuzzy sets theory. A group of 1053 patients was used to develop the model and another group of 1045 patients was used to test it. Receiver operating characteristic curves were used to compare the performance of the fuzzy model against expert physician opinions, and showed that the performance of the fuzzy model was equal or superior to that of the physicians. Therefore, we conclude that the fuzzy model could be a useful tool to assist the general practitioner in the selection of patients for MPS.
\end{abstract}

Key words

- Fuzzy model

- Coronary disease

- Scintigraphy

- Myocardial perfusion 


\section{Introduction}

Coronary artery disease (CAD) is a worldwide leading cause of death. Early detection is important to prevent death and disability. The standard reference method for evaluating critical partial occlusions is coronary arteriography, a catheterization technique which is invasive, time consuming, and costly. There are noninvasive approaches for the early detection of CAD. One of the most important noninvasive techniques is myocardial perfusion scintigraphy (MPS) (1). However, this technique can also be costly and should be performed when a reasonable doubt is left after the use of other less sophisticated approaches. Therefore, MPS should be applied only when a clear increase in information is expected to be provided when added to the information that is available before performing the test (2).

Noninvasive investigation of CAD is based on a sequential analysis of the risk factors, on the results of the treadmill test (TT) and the MPS. Many investigators have demonstrated that the appropriate diagnostic applications of MPS are for patients who have an intermediate likelihood of disease (2-6). It has been suggested (6) that patients with a low likelihood of disease might not be tested or might simply undergo the TT. When the TT is negative the patient is simply followed up. If the TT is positive, the MPS is appropriate. Patients with an intermediatehigh likelihood of coronary disease should be directly submitted to MPS. Patients with a high likelihood of CAD should likewise be referred to the catheterization laboratory, if an invasive approach is favored by the referring physician and the patient.

Although these algorithms are useful, they have some problems when applied in clinical practice. Since they are based on Bayes' inference, the challenge is how to properly classify each patient in terms of pre-test numerical probability. Although the authors of these algorithms give information on how to classify patients, this information is often not sufficient for the proper classification and thus is seldom used in daily practice. Additional problems are the wide gamut of values for the intermediate probability group, which ranges from 0.15 to 0.85 in some algorithms, and the boundary between categories. For example, in one of these algorithms (6), a patient with 0.14 probability of CAD will be classified in a different group than a patient with 0.15 probability, even though the difference between them is only 0.01 . Conversely, a patient with 0.50 probability will be classified in the same category as a patient with 0.15 probability, though the difference between them is 0.35 .

Another drawback of some of these algorithms is the classification of TT as either positive or negative. Although this test could be classified in this way, in clinical practice the results will be commonly interpreted on a scale from very positive to very negative results. Nowadays, it is possible to classify patients using scores that can have a scale of more than 20 points (7).

Therefore, the approaches based on a precise numerical definition of probability and on the classical set theory do not seem to be the most adequate to solve the problem of classification of patients that should undergo MPS.

Fuzzy logic is a superset of conventional (Boolean) logic that has been extended to handle the concept of partial truth - truth values between "completely true" and "completely false". It was introduced by Dr. Lotfi Zadeh in the 1960's (8) as a means to model the uncertainty of natural language. Since then fuzzy sets theory has been applied in numerous areas. It is especially suited to medical applications, since much of the information required for medical decisionmaking is uncertain. Hudson and Cohen (9) outlined the sources of uncertainty in medical decision-making and concluded that fuzzy logic could provide the adequate approach 
to handle medical problems.

Particularly in the field of cardiovascular investigation, Kalmanson and Stegall (10) performed an extensive analysis of medical decision-making and concluded that the classic, formal, quantitative approach to medical research and clinical decision threatens us with the danger of drowning in excessive data, and that a new conceptual and methodological approach based on the concept of fuzzy sets offers an alternative decision making path.

On the basis of the above considerations, the present study was conceived to propose and test a fuzzy model for selecting patients to be submitted to MPS for the diagnosis of CAD.

\section{Subjects and Methods}

\section{Study population}

Data on 2101 patients (1559 males and 542 females - mean age 53) submitted to MPS performed for the diagnosis of CAD were collated for analysis from June 2000 to June 2003. None of the patients had a previous history of myocardial infarction, coronary artery bypass graft surgery (CABG) or percutaneous transluminal coronary angioplasty (PTCA). Also excluded from the study group were patients using digoxin, patients presenting a left bundle branch block and patients presenting arrhythmic patterns that could decrease the accuracy of the treadmill stress test. All performed a TT using Bruce, Bruce Modified or Ellestad protocols and all achieved at least $85 \%$ of the maximal heart rate established for their age.

\section{Collection and classification of clinical and epidemiological data}

A cardiologist interviewed all patients just before the TT. The following aspects of their epidemiological and clinical history were assessed: age, sex, systolic blood pressure, cigarette smoking, diabetes, blood cho- lesterol level, chest pain and its characteristics. All of this information was integrated with the use of a modified version of a score derived from the Framingham study database (11-15) and presented as a table by Grundy et al. (16). This modification in the score derived from Framingham study database was made to integrate the chest pain criterion into the score and to adjust it to the characteristics of our patient population. This adjustment consisted of assigning different points to some of the risk factors and was based on a previous analysis (oral presentation, "V Simpósio Ibero-Americano de Cardiologia Nuclear", Florianópolis, December 5-7, 2002). The final score used here ranges from -8 to 26 and is presented in Table 1.

\section{Treadmill test and myocardial perfusion data acquisition and processing}

The nuclear medicine physician classified the MPS as normal ( $N=2017)$ or abnormal $(\mathrm{N}=84)$.

The Duke score was used for the analysis of the treadmill stress test (7). This score is a composite of the following TT criteria: metabolic equivalents, amount of ST segment deviation in millimeters, and the presence of exercise angina (see equation below). The probability of CAD decreases with increasing Duke score.

Equation. Duke score = metabolic equivalents - $(5 \mathrm{x}$ amount of ST segment deviation in millimeters) - ( $4 \mathrm{x}$ exercise angina index $)$, where angina index $=0$ for none, 1 for nonlimiting and 2 for limiting angina.

\section{Follow-up}

Eighty-one of the 84 patients with abnormal scintigraphy were followed up for a mean period of 20 months. Data for the three who were lost to follow-up were not included in this study. Thirty-six (43\%) underwent CABG or PTCA. 


\begin{tabular}{|c|c|c|}
\hline \multirow[t]{2}{*}{ Risk factors } & \multicolumn{2}{|c|}{ Risk points } \\
\hline & Men & Women \\
\hline \multicolumn{3}{|l|}{ Age (years) } \\
\hline$<34$ & -2 & -6 \\
\hline $35-39$ & -1 & -3 \\
\hline $40-44$ & 1 & -1 \\
\hline $45-49$ & 2 & 1 \\
\hline $50-54$ & 2 & 1 \\
\hline $55-59$ & 3 & 2 \\
\hline $60-64$ & 3 & 2 \\
\hline $65-69$ & 3 & 2 \\
\hline$>70$ & 4 & 4 \\
\hline \multicolumn{3}{|c|}{ Total cholesterol (mg/dL) } \\
\hline$<169$ & -1 & -1 \\
\hline 169-199 & 1 & 0 \\
\hline $200-239$ & 1 & 1 \\
\hline $240-279$ & 2 & 1 \\
\hline$>279$ & 2 & 2 \\
\hline \multicolumn{3}{|c|}{ HDL cholesterol (mg/dL) } \\
\hline$<35$ & 3 & 2 \\
\hline $35-44$ & 1 & 1 \\
\hline $45-49$ & 1 & 1 \\
\hline $50-59$ & 0 & 0 \\
\hline$>59$ & 0 & 0 \\
\hline \multicolumn{3}{|c|}{ Systolic blood pressure $(\mathrm{mmHg})$} \\
\hline$<120$ & 0 & -1 \\
\hline $120-129$ & 0 & 0 \\
\hline $130-139$ & 1 & 1 \\
\hline $140-159$ & 2 & 1 \\
\hline$>160$ & 3 & 3 \\
\hline \multicolumn{3}{|l|}{ Diabetes } \\
\hline No & 0 & 0 \\
\hline Yes & 4 & 6 \\
\hline \multicolumn{3}{|l|}{ Smoker } \\
\hline No & 0 & 0 \\
\hline Yes & 2 & 2 \\
\hline \multicolumn{3}{|l|}{ Chest pain } \\
\hline No & 0 & 0 \\
\hline Atypical & 0 & 0 \\
\hline Typical & 8 & 6 \\
\hline
\end{tabular}

This table is based on a previous one created by Grundy et al. (16) and was modified to include chest pain as a risk factor and to adjust the risk points to our patient population.

\section{Decision model construction}

To construct a decision model, patients were further randomly distributed into two groups. The first group (group 1), comprising 1053 patients $(757$ males and 296 females, mean age 53, of which 41 presented abnormal scintigraphy and 17 underwent CABG or PTCA), was used to build the fuzzy decision system and the second group (group 2), comprising the remaining 1045 patients (802 males and 243 females, mean age 53, of which 40 had abnormal scintigraphy and 19 underwent CABG or PTCA), was used to check the accuracy of this system.

We started the construction of the decision model using a scatter plot of the distribution of the results of the 1053 MPS in group 1 . The axes of the scatter plot were the clinical-epidemiological score (y-axis) and the Duke score (x-axis). The patients were classified according to the results of scintigraphy and follow-up.

Two medical specialists, a nuclear medicine physician and a cardiologist, agreed on the definition of the fuzzy sets and membership functions for each of the scores (Figure 1).

Once the sets were defined, this information was transferred to the fuzzy toolbox of the Matlab 6.1 software (2001 - The MathWorks - http://www.mathworks.com) and the specialists adjusted the fuzzy sets membership functions and defined the fuzzy rules, the output variables and the membership functions of the outputs.

The final fuzzy sets membership functions are presented in Table 2 and the fuzzy rules are presented in Table 3.

Sugeno-type fuzzy processing was used (17; Figure 2). The Sugeno, or TakagiSugeno-Kang method of fuzzy inference, first introduced in 1985 (18), is a type of fuzzy inference in which the consequent of each rule is a linear combination of the inputs, and the output is a weighted linear combination of the consequents. 
Table 2. Fuzzy sets membership functions.

\begin{tabular}{|c|c|c|c|c|c|c|c|c|}
\hline & if & then & if & then & if & then & if & then \\
\hline \multicolumn{9}{|l|}{ Duke score } \\
\hline Lowest & $x \leq-13.4$ & $y=1$ & $-13.4<x \leq-3.84$ & $y=(x--3.84) /(-13.4--3.84)$ & $x>-3.84$ & $y=0$ & - & - \\
\hline Very low & $x \leq-11.8$ & $y=0$ & $-11.8<x \leq-6.51$ & $y=(x--11.8) /(-6.51--11.8)$ & $-6.51<x \leq-0.37$ & $y=(x--0.37) /(-6.51--0.37)$ & $x>-0.37$ & $y=0$ \\
\hline Low & $x \leq-4.6$ & $y=0$ & $-4.6<x \leq 0.68$ & $y=(x--4.6) /(0.68--4.6)$ & $0.68<x \leq 7.99$ & $y=(x-7.99) /(0.68-7.99)$ & $x>7.99$ & $y=0$ \\
\hline Intermediate & $x \leq 0.89$ & $y=0$ & $0.89<x \leq 5.77$ & $y=(x-0.89) /(5.77-0.89)$ & $5.77<x \leq 11.1$ & $y=(x-11.1) /(5.77-11.1)$ & $x>11.1$ & $y=0$ \\
\hline High & $x \leq 7.99$ & $y=0$ & $7.99<x \leq 11.3$ & $y=(x-7.99) /(11.3-7.99)$ & $11.3<x \leq 16.4$ & $y=(x-16.4) /(11.3-16.4)$ & $x>16.4$ & $y=0$ \\
\hline Very high & $x \leq 11.1$ & $y=0$ & $11.1<x \leq 15.3$ & $y=(x-11.1) /(15.3-11.1)$ & $x>15.3$ & $y=1$ & - & - \\
\hline \multicolumn{9}{|c|}{$x=$ Duke score; $y=$ degree of membership to the fuzzy set. } \\
\hline \multicolumn{9}{|c|}{ Clinical-epidemiological score } \\
\hline Very low & $x \leq 1.8$ & $y=1$ & $1.8<x \leq 5$ & $y=(x-5) /(1.8-5)$ & $x>5$ & $y=0$ & - & - \\
\hline Low & $x \leq 2.43$ & $y=0$ & $2.43<x \leq 5.5$ & $y=(x-2.43) /(5.5-2.43)$ & $5.5<x \leq 7.94$ & $y=(x-7.94) /(5.5-7.94)$ & $x>7.94$ & $y=0$ \\
\hline Intermediate & $x \leq 5.08$ & $y=0$ & $5.08<x \leq 8.46$ & $y=(x-5.08) /(8.46-5.08)$ & $8.46<x \leq 12.2$ & $y=(x-12.2) /(8.46-12.2)$ & $x>12.2$ & $y=0$ \\
\hline High & $x \leq 8.68$ & $y=0$ & $8.68<x \leq 12.2$ & $y=(x-8.68) /(12.2-8.68)$ & $12.2<x \leq 16.3$ & $y=(x-16.3) /(12.2-16.3)$ & $x>16.3$ & $y=0$ \\
\hline Very high & $x \leq 13$ & $y=0$ & $13<x \leq 18.9$ & $y=(x-13) /(18.9-13)$ & $x>18.9$ & $y=1$ & - & - \\
\hline
\end{tabular}

The table shows the mapping functions of the entry values (clinical-epidemiological and Duke scores) to define the membership to the fuzzy sets.

Table 3. Fuzzy rules.

\begin{tabular}{|c|c|c|c|c|c|}
\hline Rule No. & If & Clinical-epidemiological & and & Duke & Degree of usefulness of scintigraphy \\
\hline 1 & & Very low & & - & Low \\
\hline 2 & & Low & & Lowest & High \\
\hline 3 & & Low & & Very low & Intermediate high \\
\hline 4 & & Low & & Low & Intermediate \\
\hline 5 & & Low & & Intermediate & Intermediate low \\
\hline 6 & & Low & & High & Low \\
\hline 7 & & Intermediate & & Lowest & Very high \\
\hline 8 & & Intermediate & & Very low & High \\
\hline 9 & & Intermediate & & Low & Intermediate high \\
\hline 10 & & Intermediate & & Intermediate & Intermediate low \\
\hline 11 & & Intermediate & & High & Low \\
\hline 12 & & High & & Lowest & Very high \\
\hline 13 & & High & & Very low & High \\
\hline 14 & & High & & Low & High \\
\hline 15 & & High & & Intermediate & Intermediate low \\
\hline 16 & & High & & High & Intermediate low \\
\hline 17 & & Very high & & Lowest & Very high \\
\hline 18 & & Very high & & Very low & Very high \\
\hline 19 & & Very high & & Low & Very high \\
\hline 20 & & Very high & & Intermediate & Intermediate high \\
\hline 21 & & Very high & & High & Intermediate low \\
\hline 22 & & - & & Very high & Low \\
\hline
\end{tabular}

The table shows the 22 rules created by specialists. The rules have two fuzzy antecedents (clinicalepidemiological and Duke scores) and one consequent (degree of usefulness of scintigraphy). 


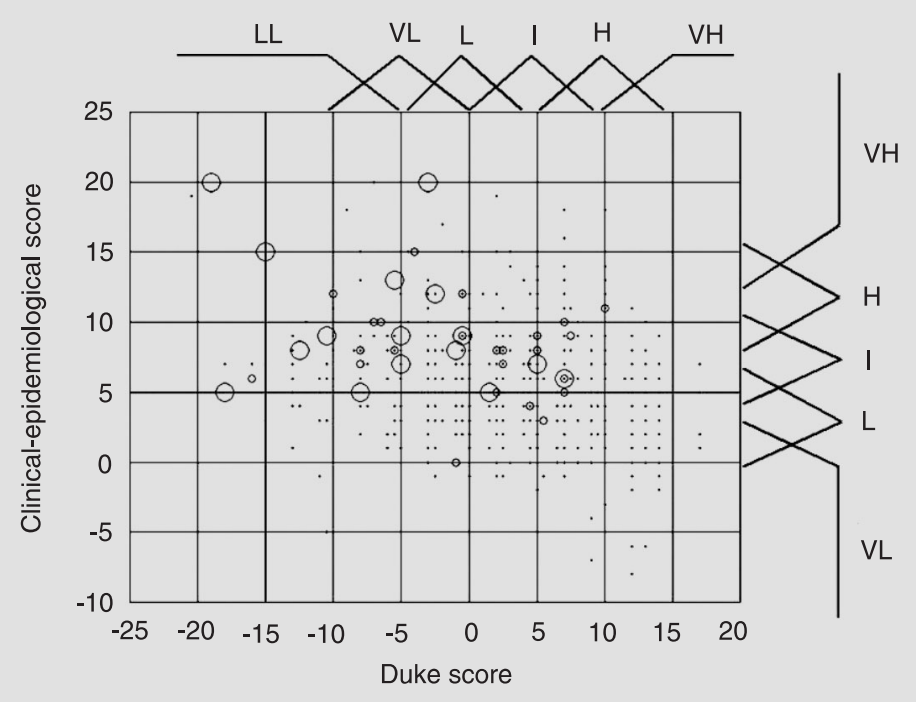

Figure 1. Scatter plot distribution of the results of myocardial perfusion scintigraphy showing the fuzzy sets and membership defined by two specialists. The Duke score ( $\mathrm{x}$-axis) and clinical-epidemiological score (y-axis) were divided into fuzzy sets: lowest (LL), very low $(\mathrm{VL})$, low (L), intermediate (I), high (H), and very high (VH) (see Table 2). Dot = normal perfusion; small circle $=$ abnormal perfusion without events; large circle $=$ abnormal perfusion with events. Events = coronary artery bypass graft surgery or percutaneous transluminal coronary angioplasty.

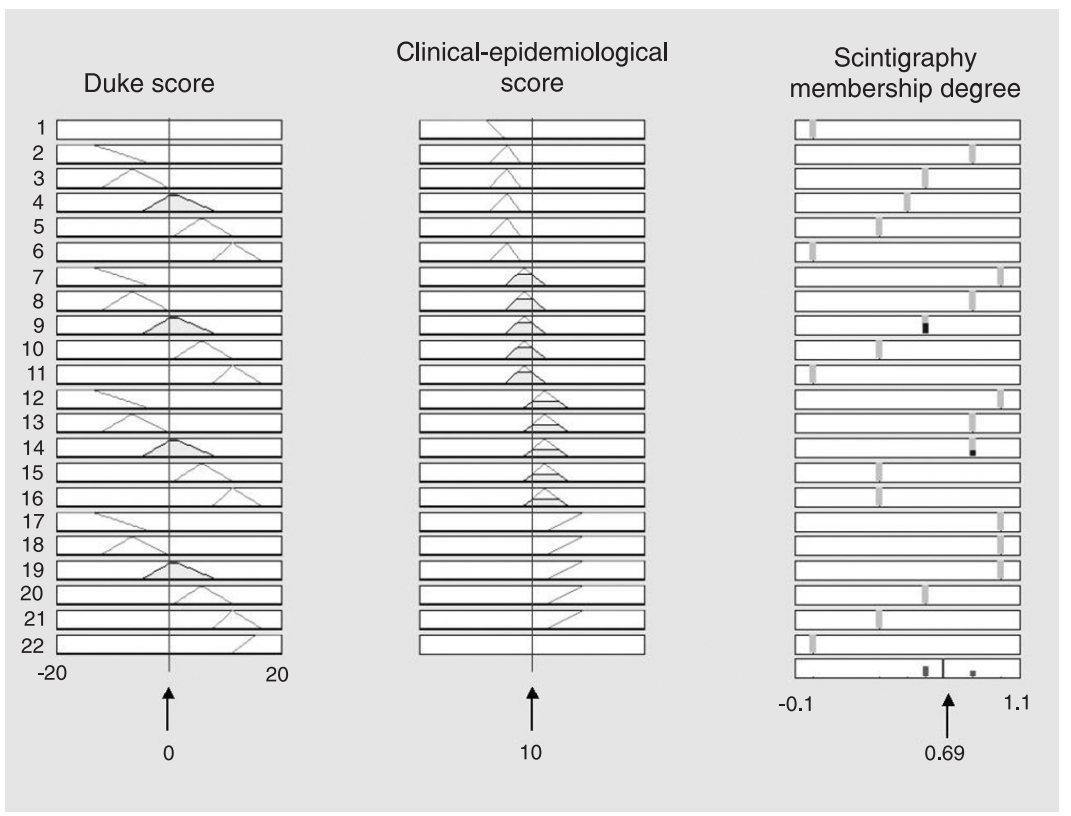

Figure 2. An example of a hypothetical patient presenting a Duke score of 0 and a clinicalepidemiological score of 10 . Two fuzzy rules are activated (9 and 14) with different degrees. The final fuzzy score for this patient will be 0.69 (arrow). This value is derived from the weighted mean of the two activated rule outputs.
In our model, the output variable is the degree of utility of scintigraphy and comprises six membership functions: very high, high, intermediate high, intermediate, intermediate low, and low. We used the following constants (singletons) to represent the membership functions: $1,0.85,0.6,0.5,0.35$, and 0 for very high, high, intermediate high, intermediate, intermediate low, and low, respectively.

The membership grades or, in other words, the degrees of utility of MPS based on the Duke and the clinical-epidemiological scores are shown in Figure 3 as a third dimension.

\section{Decision model performance}

The receiver operating characteristic (ROC) curve was used to check the sensitivity and specificity of the fuzzy scores for abnormal MPS. All patients with positive scintigraphy who further underwent CABG or PTCA were considered to be positive. The patients with normal scintigraphy and the patients with abnormal scintigraphy but with normal follow-up were considered to be negative. This analysis was performed in the second group of patients (group 2).

In addition, the performance of the fuzzy decision model was compared against the opinion of physicians with experience in both nuclear medicine and cardiology.

For the comparison with the physicians, a group of 300 patients was randomly generated from group 2. Three physicians (a nuclear medicine physician with experience in MPS, a senior cardiologist with experience in MPS and another senior cardiologist who was chosen to differ from the first in regard to experience with MPS in order to provide a view closer to that of the average cardiologist) independently classified the 300 patients. In a grade-of-membership fashion, these physicians established a degree of utility of scintigraphy (ranging from 0 to 100) based on the analysis of all clinical- 
epidemiological and TT data available for each patient.

The ROC curve for each physician was compared with the ROC curve of the fuzzy model for the same group of 300 patients.

The areas under the ROC curves and their 95\% confidence interval $(95 \% \mathrm{CI})$ were calculated with the SPSS 11.0 software (SPSS Inc., Chicago, IL, USA). The statistical significance of the difference among the areas under the ROC curve was calculated with the MedCalc software (Mariakerke, Belgium).

\section{Results}

The area under the ROC curve was 0.95 (95\% CI: 0.93-0.97) for the comparison of the fuzzy model against actual status in the follow-up of group 2.

Using a fuzzy score of at least 0.55 as a threshold for ordering scintigraphy, the model will indicate this test to all patients with abnormal scintigraphy results who further underwent PTCA or CABG and will exclude from the test $85 \%$ of the patients with either normal scintigraphy or abnormal scintigraphy but without events (CABG or PTCA). Table 4 presents the sensitivity and specificity of different fuzzy score threshold values. It is possible to further increase the specificity of the model by using scores higher than 0.55 but with a disproportionate decrease in sensitivity.

The ROC curve areas were: 0.94 (95\% CI: 0.91-0.97) - fuzzy score; 0.83 (95\% CI: 0.76-0.91) - physician 1; 0.89 (95\% CI: 0.810.97 ) - physician 2; 0.67 (95\% CI: $0.57-$ 0.77 ) - physician 3 (Figure 4) for the comparison of medical opinion against the fuzzy score created.

The statistical significance of the difference among the areas under the ROC curves is presented in Table 5 .

\section{Discussion}

In the era of healthcare reform, the pres- sure to save the money spent on unnecessary tests is increasing progressively. Therefore, it is important to define when a diagnostic test should be performed. However, the definition of the exact situation when a test should be ordered is frequently difficult to identify. In this new environment, the physician has to be constantly pondering the cost of performing an unnecessary test against the risk of not performing a necessary one. In the diagnosis of CAD this situation is a

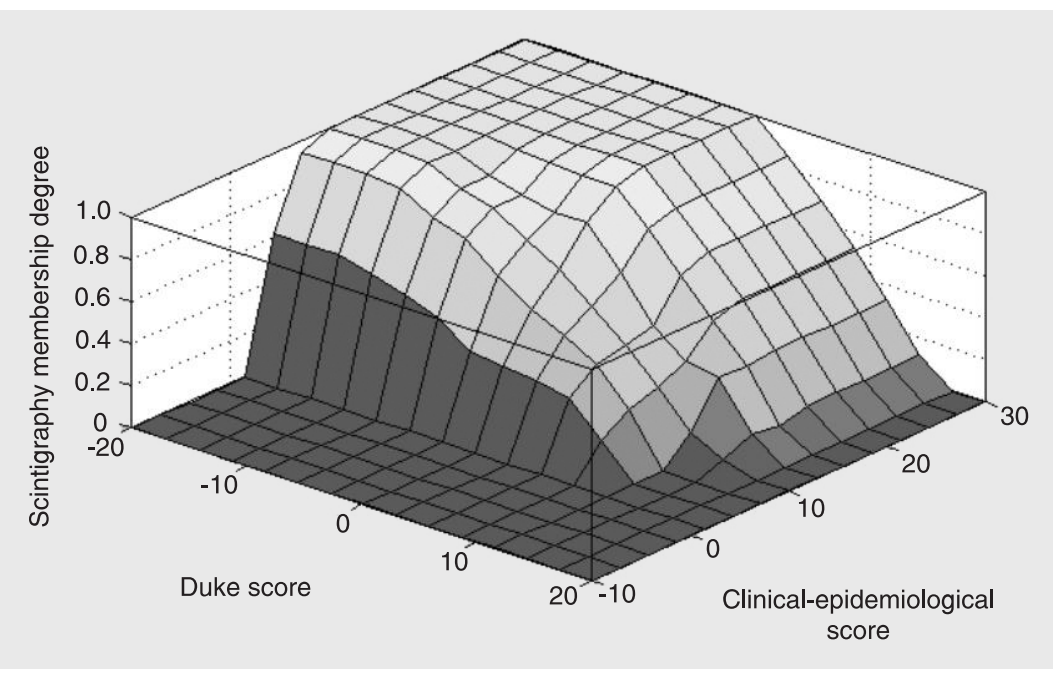

Figure 3. Three-dimensional representation of the final results of the membership degree for the set of patients that should perform scintigraphy, based on fuzzy rules defined by the specialist and the result of Duke and clinical-epidemiological scores.

Table 4. Sensitivity and specificity of different fuzzy score thresholds for the selection of patients who should undergo myocardial perfusion scintigraphy.

\begin{tabular}{lcc}
\hline Fuzzy score & Sensitivity (\%) & Specificity (\%) \\
\hline 0.10 & 100 & 41 \\
0.20 & 100 & 49 \\
0.30 & 100 & 57 \\
0.37 & 100 & 61 \\
0.40 & 100 & 68 \\
0.50 & 100 & 81 \\
0.55 & 100 & 85 \\
0.60 & 84 & 90 \\
0.70 & 63 & 92 \\
0.80 & 53 & 95 \\
0.90 & 32 & 98 \\
0.98 & 26 & 100 \\
\hline
\end{tabular}

The 0.55 fuzzy score value presents $100 \%$ sensitivity for truly abnormal myocardial perfusion, with specificity of $85 \%$. 
particular source of concern because of the complexity of the diagnostic algorithm and the risk of a misdiagnosis. Over the last decades, some approaches have been proposed to help physicians to solve these problems. Diamond et al. (19) proposed a computer-assisted diagnosis for the noninvasive
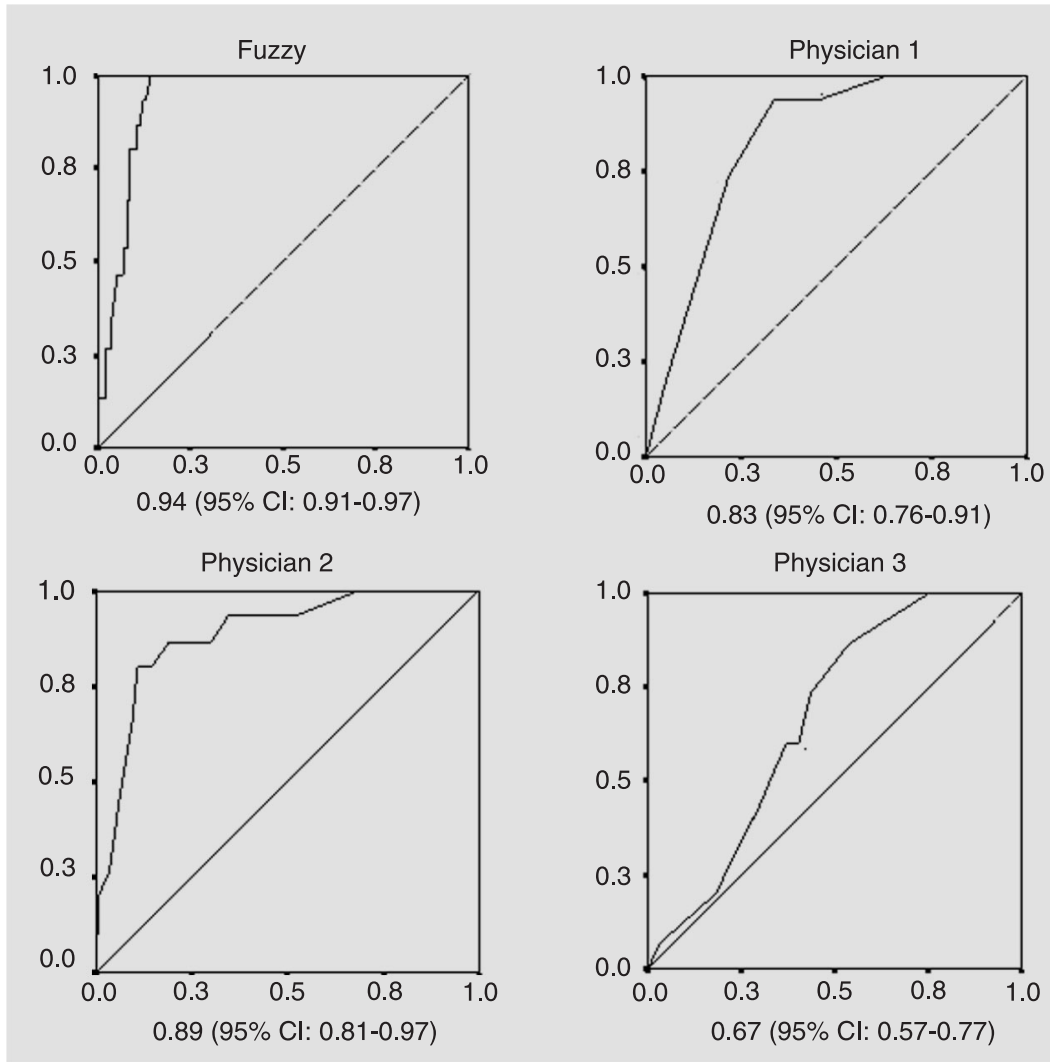

Figure 4. ROC curves for fuzzy score and physicians. The x-axis is 1 minus the specificity (the false-positive rate) and the $y$-axis is the sensitivity (the true-positive rate). The diagonal line on the graph from $(0,0)$ in the lower left hand corner to $(1,1)$ in the upper right hand corner reflects the characteristics of a test with no discriminating power. Below each graphical are shown the area under the ROC curve and the respective $95 \%$ confidence interval $(\mathrm{Cl})$.

Table 5. Statistical significance ( $\mathrm{P}$ value) of the difference among the areas under the ROC curves presented in Figure 4.

\begin{tabular}{lcccc}
\hline & Fuzzy & Physician 1 & Physician 2 & Physician 3 \\
\hline Fuzzy & 1.00 & 0.09 & 0.25 & $<0.01^{*}$ \\
Physician 1 & & 1.00 & 0.27 & $0.04^{*}$ \\
Physician 2 & & 1.00 & 0.07 \\
Physician 3 & & & 1.00 \\
\hline
\end{tabular}

${ }^{*} \mathrm{P}<0.05$ (Wilcoxon test) evaluation of patients with suspected CAD. This program employed a database of more than 60,000 patients from the medical literature to calculate the probability of CAD according to Bayes' theorem (20). Although this system proved to be an accurate means for quantifying the prevalence of angiographic CAD, due to the risk of multi-vessel disease and the incidence of morbid coronary events in the year ensuing test (19), it has not been used regularly in clinical practice. Possible reasons for its under-utilization are the computational complexity of the analysis and the level of knowledge required for the general practitioner to use the system. A conceptual and methodological approach based on fuzzy sets offers an alternative decision process that permits the classification system to take the opinion of expert physicians into account, thereby meeting the real clinical needs.

The use of fuzzy sets theory in the medical field is relatively new, but it has been frequently demonstrated to be useful to solve some medical problems $(9,21,22)$, particularly in the investigation of CAD (10,23-25). In the present study, we developed an algorithm to classify the patients who should perform MPS using the fuzzy sets theory. The model was developed using more than one thousand patients and was tested with a similar number of patients. The model was found to be accurate for classification and, when compared with a group of physicians with expertise in nuclear medicine and cardiology, it proved to be at least as accurate as these professionals.

It is interesting to note that one of the physicians presented a ROC curve area significantly below that of the model. This physician was the cardiologist who had the least experience with scintigraphy and who had been asked to participate in order to provide the level of ascertainment expected from cardiologists with limited experience. Thus, while the fuzzy model is undistinguishable from experts in scintigraphy, it apparently 
scores better than the cardiologists with tool for general practitioners and general cardiologists to decide whether a patient should or should not undergo MPS.

Another important question to be discussed is the availability of the fuzzy model to a general practitioner. Based on the information in Tables 2, 3, and 4, it is possible to develop a fuzzy model like the one used in the present project using an Excel work sheet (Microsoft). However, for general practitioners who are not familiarized with computers, it is also possible to calculate the fuzzy score using an Excel work sheet available at the homepage of the Laboratório de Epidemiologia e Estatística (LEE) of Instituto
Dante Pazzanese de Cardiologia (http:// www.lee.dante.br/pesquisa/planilha_fuzzy/ index.htm).

The model based on a fuzzy set theory described here proved to be accurate for the classification of the patients that should perform MPS for CAD diagnosis and represents an alternative approach to create artificial intelligence systems that could assist the general practitioner to select patients to be submitted to sophisticated diagnostic tests.

\section{Acknowledgments}

We would like to thank the Fleury Institute for technical support to this study.

\section{References}

1. Ritchie JL, Bateman TM, Bonow RO et al. (1995). Guidelines for clinical use of cardiac radionuclide imaging. Report of the American College of Cardiology/American Heart Association Task Force on Assessment of Diagnostic and Therapeutic Cardiovascular Procedures (Committee on Radionuclide Imaging), developed in collaboration with the American Society of Nuclear Cardiology. Journal of the American College of Cardiology, 25: 521-547.

2. Berman DS, Kiat H, Friedman JD et al. (1995). Clinical applications of exercise nuclear cardiology studies in the era of healthcare reform. American Journal of Cardiology, 75: 3D-13D.

3. Maddahi J \& Gambhir SS (1997). Cost-effective selection of patients for coronary angiography. Journal of Nuclear Cardiology, 4: S141S151.

4. Hlatky M, Botvinick E \& Brundage B (1982). Diagnostic accuracy of cardiologists compared with probability calculations using Bayes' rule. American Journal of Cardiology, 49: 1927-1931.

5. Melin JA, Wijns W, Vanbutsele RJ et al. (1985). Alternative diagnostic strategies for coronary artery disease in women: demonstration of the usefulness and efficiency of probability analysis. Circulation, 71: $535-542$.

6. Berman D, Hachamovitch R, Lewin $\mathrm{H}$ et al. (1997). Risk stratification in coronary artery disease: implications for stabilization and prevention. American Journal of Cardiology, 79: 10-16.

7. Gibbons RJ, Balady GJ, Beasley JW et al. (1997). ACC/AHA Guidelines for Exercise Testing. A report of the American College of Cardiology/American Heart Association Task Force on Practice Guidelines (Committee on Exercise Testing). Journal of the American College of Cardiology, 30: 260-311.

8. Zadeh LA (1965). Fuzzy sets. Information and Control, 8: 338-352.

9. Hudson DL \& Cohen ME (1994). Fuzzy logic in medical expert systems. IEEE Engineering in Medicine and Biology, 6: 693-698.

10. Kalmanson D \& Stegall HF (1975). Cardiovascular investigations and fuzzy sets theory. American Journal of Cardiology, 35: 80-84.
11. Anderson KM, Wilson PW, Odell PM et al. (1991). An updated coronary risk profile. A statement for health professionals. Circulation, 83: 356-362.

12. Feinleib M, Kannel WB, Garrison RJ et al. (1975). The Framingham Offspring Study. Design and preliminary data. Preventive Medicine, 4: 518-525.

13. Garrison RJ, Kannel WB, Feinleib M et al. (1978). Cigarette smoking and HDL cholesterol: the Framingham offspring study. Atherosclerosis, 30: 17-25.

14. Kannel WB, Feinleib M, McNamara PM et al. (1979). An investigation of coronary heart disease in families. The Framingham offspring study. American Journal of Epidemiology, 110: 281-290.

15. Wilson PW, D'Agostino RB, Levy D et al. (1998). Prediction of coronary heart disease using risk factor categories. Circulation, 97: 1837-1847.

16. Grundy SM, Pasternak R, Greenland $P$ et al. (1999). AHA/ACC scientific statement: Assessment of cardiovascular risk by use of multiple-risk-factor assessment equations: a statement for healthcare professionals from the American Heart Association and the American College of Cardiology. Journal of the American College of Cardiology, 34: 1348-1359.

17. Reznik $L$ (1997). The structure and operation of a fuzzy controller. In: Reznik L (Editor), Fuzzy Controllers. Elsevier Books, Oxford, UK.

18. Sugeno M (1985). Industrial Applications of Fuzzy Control. Elsevier Science Inc., New York.

19. Diamond GA, Staniloff HM, Forrester JS et al. (1983). Computerassisted diagnosis in the noninvasive evaluation of patients with suspected coronary artery disease. Journal of the American College of Cardiology, 1: 444-455.

20. Diamond GA \& Forrester JS (1979). Analysis of probability as an aid in the clinical diagnosis of coronary artery disease. New England Journal of Medicine, 300: 1350-1358.

21. Reis MA, Ortega NR \& Silveira PS (2004). Fuzzy expert system in 
the prediction of neonatal resuscitation. Brazilian Journal of Medical and Biological Research, 37: 755-764.

22. Pereira JC, Tonelli PA, Barros LC et al. (2004). Clinical signs of pneumonia in children: association with and prediction of diagnosis by fuzzy sets theory. Brazilian Journal of Medical and Biological Research, 37: 701-709.

23. Zahan S (2001). A fuzzy approach to computer-assisted myocardial ischemia diagnosis. Artificial Intelligence in Medicine, 21: 271-275.
24. Akay YM, Akay M, Welkowitz W et al. (1994). Noninvasive detection of coronary artery disease. IEEE Engineering in Medicine and Biology, 6: 761-764.

25. Peters RM, Shanies SA \& Peters JC (1995). Fuzzy cluster analysis of positive stress tests, a new method of combining exercise test variable to predict extent of coronary artery disease. American Journal of Cardiology, 76: 648-651. 